\begin{abstract}
Натрийуретические пептиды были открыты в 50-70-е г2. ХХ в. Натрийуретический пептид типа В (ВNP) оказался наиболее диагностически и прогностически значимым, поскольку он секретируется непосредственно в желудочках сердиа и более точно отражает нагрузку на миокард. В ходе различных исследований была продемонстрирована высокая предсказательная значимость повышения содержания ВNP при острой декомпенсации сердечной недостаточности, а также у пациентов с хронической сердечной недостаточностью в крупном исследовании Val-HеFT. Показано, что мониторирование уровня мозгового натрийуретического пептида (NT-ргоBNP) может быть использовано для подбора оптимальных лекарственных комбинаций в каждом отдельном случае и тем самым, поможет повлиять на течение и исход заболевания, а также снизить стоимость лечения. Следующим шагом в изучении ВNP стали попытки использования его в лечении сердечной недостаточности. Длительная терапия BNP (препарат несиритид) улучшала ремоделирование левого желудочка у пациентов со стабильной сердечной недостаточностью. В настоящее время определение содержания BNP и NT-ргоBNP используют для диагностики и ведения пациентов с сердечной недостаточностью.
\end{abstract}

Ключевые слова: сердечная недостаточность, мозговой наутрийуретический пептид, диагостика, лечение, несиритид.

(Для цитирования: Бурнашева Г.А., Напалков Д.А. Натрийуретические пептиды: использование в современной кардиологии Вестник РАМН. 2015; 70 (5): 568-572. Doi: 10.15690/vramn.v70.i5.1443)

\section{История}

История открытия натрийуретических пептидов началась в 50-70-е гг. XX в., когда В. Kisch, а затем J.P. Marie обнаружили в предсердиях морских свинок секреторные гранулы, которые формировались в ответ на водно-электролитные изменения в ткани [1, 2]. В 1956 г. физиологи J.P. Henry и J.W. Pearce в эксперименте продемонстрировали увеличение диуреза у собак после баллонной дилатации левого предсердия [3]. В 1981 г. А.J. de Bold установил, что инъекции гомогенизированных экстрактов ткани предсердий крысам способствуют повышенной экскреции натрия и воды и приводят к снижению системного артериального давления [4]. Уже через 3 года стало известно строение предсердного натрийуретического пептида (atrial natriuretic peptide, ANP), а спустя еще 4 года, в 1988 г., из мозга свиньи был получен другой натрийуретический пептид, названный мозговым (brain natriuretic peptide, $\mathrm{BNP})$. Впоследствии стало известно, что его синтезируют в большей степени желудочки сердца [5-7].
Далее, в 1990 г., был выделен натрийуретический пептид С-типа (C-type natriuretic peptide, CNP), который отличается по своей структуре от ANP и BNP и в большей степени относится к центральной нервной системе и эндотелию сосудов (его также называют гиперполяризующий фактор эндогенного происхождения endothelium-derived hyperpolarizing factor, EDHF) [8]. Предполагается, что CNP действует локально как паракринный / аутокринный регулятор, поскольку быстро выводится из кровотока и потому определяется в плазме в очень низких концентрациях [9]. Пептид С-типа не обладает таким мощным диуретическим эффектом, который наблюдают при действии ANP и BNP [9-11]; при этом установлено, что экзогенный CNP является сильным артериальным и венозным дилататором [8, 12 , 13]. Структурный гомолог яда змеи - зеленой мамбы (Dendroaspis angusticeps) - натрийуретический пептид $\mathrm{D}$-типа недавно обнаружен в плазме и предсердиях человека, но его происхождение и физиологическая роль до конца не известны $[7,14,15]$.

\author{
G.A. Burnasheva, D.A. Napalkov \\ Sechenov First Moscow State Medical University, Moscow, Russian Federation
}

\title{
Natriuretic Peptides: Role in Current Cardiology
}

Natriuretic peptides were discovered in 50-70s of the XX century. BNP was more diagnostically and prognostically significant, as it is secreted directly into the ventricles of the heart. The studies demonstrated a high predictive value of increasing the level of BNP in acute decompensation of heart failure and in patients with chronic heart failure in a study of Val-HeFT. It was demonstrated that monitoring the level of NT-proBNP can be used for the selection of optimal therapy, affect the course and outcome of the disease, and reduce the cost of treatment. The next step in learning BNP was to undertake attempts of their use in the therapy of heart failure. Long-term therapy BNP (drug nesiritide) improved left ventricular remodelling in patients with stable heart failure. Currently the definition of the levels of BNP and NT-proBNP is used for the diagnosis and management of patients with heart failure.

Key words: heart failure, brain nutriuretic peptide, diagnosis, treatment, nesiritide.

(For citation: Burnasheva G.A., Napalkov D.A. Natriuretic Peptides: Role in Current Cardiology. Vestnik Rossiiskoi Akademii Meditsinskikh Nauk = Annals of the Russian Academy of Medical Sciences. 2015; 70 (5): 568-572. Doi: 10.15690/vramn.v70.i5.1443) 


\section{Диагностическая и прогностическая значимость BNP при сердечной недостаточности}

Первые случаи увеличения концентрации предсердного натрийуретического пептида у больных сердечной недостаточностью $(\mathrm{CH})$ были зарегистрированы в 1986 г. [16]. В 1993 г. было отмечено повышение содержания как предсердного, так и мозгового натрийуретического пептида еще до появления клинической симптоматики при дисфункции левого желудочка (ЛЖ) [17, 18]. BNP выделяется непосредственно в желудочках сердца (основным пусковым механизмом этого процесса служит увеличение конечного диастолического давления), соответственно, более точно отражает нагрузку на миокард, в связи с чем он был признан более значимым для постановки диагноза и определения прогноза заболевания [19-21].

В 1997 г. М. Cowie и соавт. провели исследование (Hillingdon Heart Failure Study), участниками которого стали жители Лондона [22], страдающие хронической $\mathrm{CH}(\mathrm{XCH})$. У всех пациентов определяли концентрации обоих натрийуретических пептидов и сравнивали их с клиническими показателями (данные объективного обследования, рентгенологического исследования органов грудной клетки, трансторакальной эхокардиографии). Диагноз подтвердился в $98 \%$ случаев при концентрации ANP более 18,1 нмоль/л (62,6 нг/мл) и ВNP - более 22,2 нмоль/л (76,8 нг/мл). Специфичность теста составила $84 \%$.

T. Tsutamoto и соавт. [23] после проведения мультивариантного анализа установили, что уровень мозгового натрийуретического пептида выше 106 пг/мл у пациентов с ХСН связан с $80 \%$ вероятностью летального исхода в последующие 2 года, а при превышении порогового значения BNP плазмы в 21,2 пмоль/л (73 пг/мл) увеличение концентрации на каждые 2,9 пмоль/л (10 пг/мл) ассоциируется с возрастанием риска смерти от сердечно-сосудистых осложнений на $3 \%$.

Следующий работой, в которой оценивали концентрацию BNP, было исследование MONICA, участниками которого стали 1678 пациентов [24]. Концентрация мозгового натрийуретического пептида была значимо выше у больных с систолической дисфункцией $(76,2 \pm 23,2$ нг/мл) и диастолической дисфункцией левого желудочка $(20,3 \pm 4,7$ нг/мл), гипертрофией ЛЖ $(37,3 \pm 49,1$ нг/мл) в сравнении с контрольной группой $(9,6 \pm 0,5$ нг/мл).

После проведения анализа множества клинических показателей больных ХСН авторами была установлена зависимость концентрации BNP от таких показателей, как возраст, фракция выброса, размер левого предсердия, степень дисфункции ЛЖ.

По данным V. Cheng и соавт., которые изучали динамику содержания BNP у 72 стационарных пациентов с декомпенсированной ХCH [25], в процессе лечения концентрация BNP нарастала (в среднем на 233 пг/мл) у больных с позднее зафиксированным летальным исходом $(n=9)$; при этом у ответивших на терапию пациентов уровень BNP снизился в среднем на 215 пг/мл. Также было обнаружено соответствие между динамикой содержания BNP и изменением функционального класса СН. В результате исследования авторы выявили связь между концентрацией BNP и вероятностью повторной госпи- тализации или сердечно-сосудистой смерти в ближайшие 30 сут. Так, 90\% отрицательным прогностическим значением обладал уровень мозгового натрийуретического пептида перед выпиской менее 1220 пг/мл, 92\% менее 950 пг/мл, 94\% - менее 800 пг/мл, 96\% - менее 430 пг/мл.

G. Dао и соавт. обследовали 250 пациентов с острой декомпенсацией ХCH, у которых позитивная предсказательная ценность увеличения концентрации BNP более 23 пмоль/л (80 пг/мл) колебалась между 92 и 98\% [26].

Прогностическая значимость BNP была также отмечена в результате исследования Val-HeFT, в котором участвовали 4300 пациентов [27]. Максимальное число летальных исходов $(32,4 \%)$ было зафиксировано среди лиц, концентрация BNP плазмы которых превышала 238 пг/мл. После повторного определения содержания BNP через 4 мес было замечено, что повышение концентрации пептида более чем на $30 \%$ от исходного уровня ассоциируется с риском смерти от сердечно-сосудистой патологии в 19,1\% случаев. В группе же больных, у которых уровень пептида снизился более чем на $45 \%$, летальность составила 13,6\%. Это первое исследование, в котором подтверждена значимость контроля содержания BNP в динамике для оптимального подбора схемы лечения и определения прогноза.

\section{Острый коронарный синдром}

Монофазное увеличение концентрации BNP установили в 2004 г. M. Galvani и соавт. [28] у пациентов с острым коронарным синдромом. Была обнаружена прямая связь между степенью дисфункции ЛЖ, величиной давления заклинивания легочной артерии и концентрацией мозгового натрийуретического пептида, которая одновременно отражала общую вероятность риска летального исхода от сердечно-сосудистых событий.

\section{Контроль и коррекция кардиоваскулярной терапии в зависимости от величины BNP}

В 1999 г. в исследовании D.R. Murdoch и соавт. 20 пациентов с ХCH в течение 8 нед получали ингибиторы ангиотензинпревращающего фермента, доза которых титровалась в соответствии с клиническими данными в одной группе или значением BNP в другой [29]. Во второй группе отмечено более выраженное уменьшение частоты сердечных сокращений и повышение содержания ренина. Troughton и соавт. аналогично корректировали терапию 69 пациентам с ХСН в зависимости от результатов клинического осмотра или значений концентрации BNP и NT-proBNP в плазме крови [30]. Наблюдение проводили в течение 9,5 мес. В «клинической группе» было зафиксировано большее число сердечно-сосудистых событий, чем в группе BNP, а вероятность развития как минимум одного сердечно-сосудистого события через 6 мес наблюдения составила 53\% для «клинической группы» и $27 \%$ для группы BNP.

A.M. Richards в своем исследовании изучал значение NT-proBNP для оценки эффективности лечения карведилолом пациентов с ишемической болезнью сердца. Около 300 пациентов разделили на 2 группы 
в соответствии с содержанием у них NT-proBNP [31]. Превышение референсного значения NT-proBNP ассоциировалось с неблагоприятными исходами, при этом использование карведилола у этих пациентов оказывало отчетливый положительный эффект в сравнении с контрольной группой.

Таким образом, можно сделать вывод о том, что NTproBNP оказался не менее важным инструментом для выработки рациональной тактики в лечении пациентов с XCH, чем BNP.

\section{Использование BNP в лечении сердечной недостаточности}

Следующим шагом практического использования BNP стали попытки применения его в лечении пациентов с CH. В 1999 г. R.M. Mills и соавт. провели многоцентровое двойное слепое рандомизированное плацебоконтролируемое исследование, в котором оценивали центральную гемодинамику в течение 24 ч инфузии и 4 ч после завершения введения рекомбинантного человеческого BNP (несиритида) у больных с клинической картиной СН и признаками систолической дисфункции (фракция выброса менее 35\%). Участие приняли 103 пациента с XCH II-IV функционального класса по NYHA (New York Heart Association) [32]. Обнаружено значимое повышение фракции выброса, снижение давления заклинивания легочной артерии (ДЗЛА) в результате введения несиритида. Меньшее влияние препарат оказал на общее периферическое сосудистое сопротивление и давление в правом предсердии. Подобный положительный эффект позволил задуматься о применении несиритида в качестве препарата первой линии у пациентов с симптомами $\mathrm{CH}$.

B 2000 г. W.S. Colucci и соавт. предприняли исследование по оценке эффективности внутривенного введения несиритида при лечении декомпенсированной застойной СН. В первое исследование были включены 127 пациентов с ДЗЛА $>18$ мм рт.ст. и фракцией выброса $<2,7$ л/мин на 1 м² $^{2}$ которым внутривенно вводили несиритид в дозах 0,015 и 0,030 мг/кг в течение 6 ч. В сравнительное исследование были рандомизированы 305 человек для открытого лечения по стандартной схеме или несиритидом в течение 7 сут [33]. Через 6 ч после введения несиритида ДЗЛА снизилось на 6 (на дозе 0,015 мг/кг) и 9,6 (на дозе 0,030 мг/кг) мм рт.ст., а на фоне введения плацебо ДЗЛА увеличилось на 2 мм рт. ст. У пациентов было отмечено улучшение клинической симптоматики в 60 (на дозе 0,015 мг/кг) и 67\% (на дозе 0,030 мг/кг) случаев, только у $14 \%$ - при введении плацебо; уменьшилась одышка в 57 и 53\% (у 12\% при введении плацебо) случаев; снизилась утомляемость в 32 и $38 \%$ (у 5\% при введении плацебо) случаев. В сравнительном исследовании улучшение клинической симптоматики, уменьшение степени выраженности одышки и утомляемости было длительным при лечении несиритидом в течение 7 сут и аналогичным действию стандартной внутривенной терапии. Авторы пришли к выводу о том, что несиритид улучшает гемодинамику, общее состояние больных и эффективен для кратковременного лечения декомпенсированной застойной $\mathrm{CH}$.

В 2002 г. В.Y. James представил результаты сравнения действия несиритида и нитроглицерина в сочетании со стандартной терапией при лечении пациентов с одышкой в покое вследствие декомпенсированной застойной $\mathrm{CH}$. В исследование были включены 489 пациентов, из них 204 получали несиритид, 143 нитроглицерин и 142 плацебо в сочетании со стандартной терапией [34]. Через 3 ч было отмечено незначительное снижение ДЗЛА во всех группах (на 5,8 мм рт.ст. при использовании несиритида, на 3,8 - при терапии нитроглицерином и на $2-$ в группе плацебо). Значительная разница в улучшении по показателю одышки и в общем клиническом статусе отсутствовала как для нитроглицерина, так и для несиритида. За 24 ч ДЗЛА в группе несиритида снизилось на 8,2 , в группе нитроглицерина - на 6,3 мм рт.ст. Автором был сделан вывод о том, что при добавлении к стандартной схеме лечения декомпенсированной застойной СН несиритида улучшается гемодинамика и клиническое состояние пациентов по сравнению с введением нитроглицерина.

C.M. O'Connor и соавт. в 2011 г. оценивали динамику выраженности одышки через 6 и 24 ч (для оценки использовали шкалу Лайкерта), а также повторные госпитализации и летальные исходы в течение 30 сут при лечении несиритидом пациентов с острой декомпенсированной СН в сочетании со стандартной терапией [35]. Через 6 ч улучшение по показателю одышки в группах несиритида и плацебо отмечено на 44,5 и $42,1 \%$ случаев, соответственно; через 24 ч - на 68,2 и $66,1 \%$ соответственно; повторные госпитализации и летальные исходы - в 9,4\% случаев при лечении несиритидом и в $10,1 \%$ среди пациентов, получавших плацебо. Полученные результаты свидетельствуют о том, что несиритид не влияет на смертность и не снижает числа повторных госпитализаций, незначительно влияет на одышку, в связи с чем авторы не рекомендуют его для рутинного использования при лечении острой $\mathrm{CH}$.

Н.Н. Chen и соавт. в 2012 г. оценивали эффективность подкожного введения ВNP при лечении сердечной недостаточности: 20 пациентов с фракцией выброса менее $35 \%$ и сердечной недостаточностью II-III функционального класса по NYHA в течение 8 нед получали BNP в дозе 10 мг/кг (в контрольную группу также входило 20 пациентов) [36]. В исследуемой группе было достигнуто большее снижение систолического и диастолического объема ЛЖ, объема левого предсердия, отношения Е/Е' (отношение максимальной скорости раннего наполнения трансмитрального кровотока к максимальной скорости движения фиброзного кольца митрального клапана в раннюю диастолу), улучшение клинического статуса по шкале MLHF (Minnesota Living with Heart Failure) по сравнению с плацебо. Таким образом, длительная терапия BNP улучшает ремоделирование ЛЖ у пацентов со стабильной сердечной недостаточностью при оптимальной схеме лечения.

На основании полученных данных можно сделать вывод об эффективном улучшении гемодинамики при применении рекомбинантного человеческого BNP у пациентов с застойной $\mathrm{CH}$.

\section{Место BNP в современных рекомендациях по ведению пациентов}

с хронической сердечной недостаточностью

Исследование концентраций BNP и NT-proBNP в соответствии с современными рекомендациями исполь- 


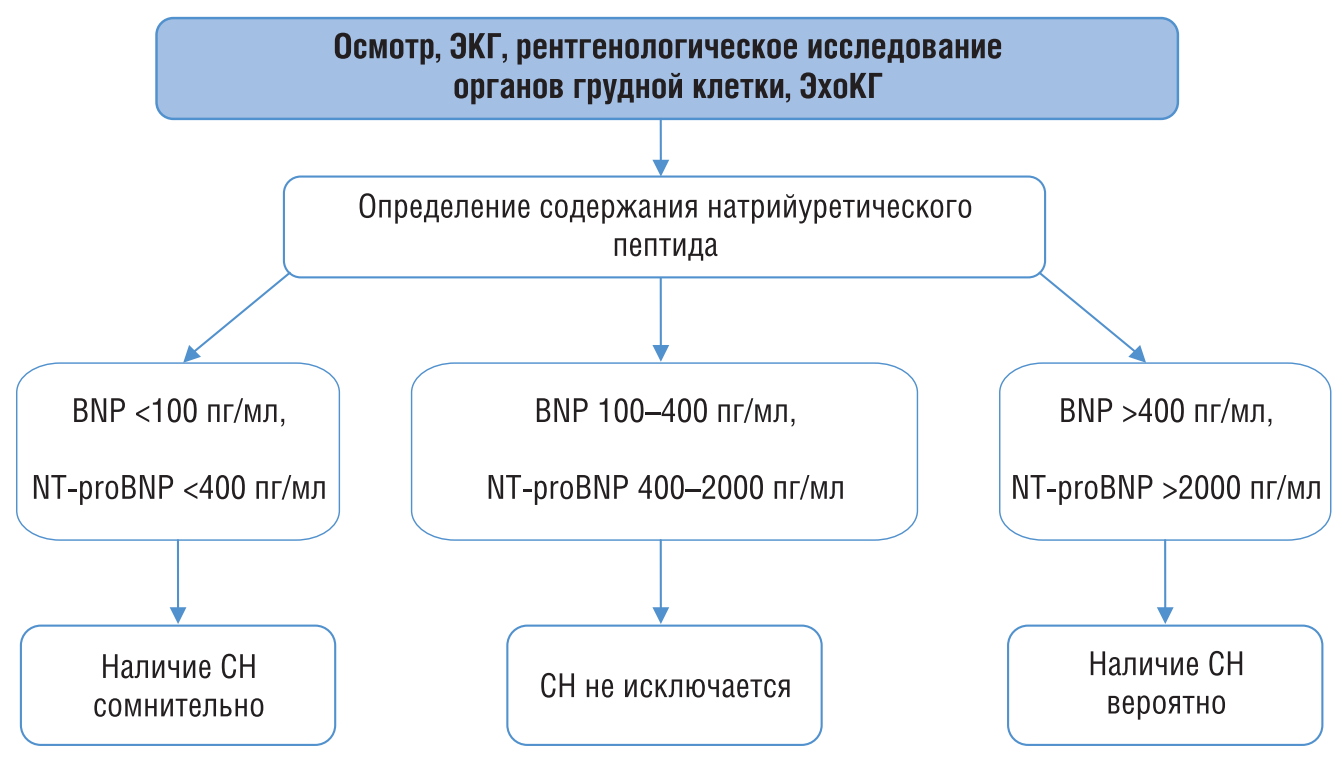

Рис. Современный алгоритм диагностики сердечной недостаточности.

Примечание. ЭКГ - электрокардиография, ЭхоКГ - эхокардиография, СН - сердечная недостаточность.

зуется в диагностике и определении оптимальной тактики ведения больных ХСН (рис.) [37].

\section{Заключение}

Установлено, что содержание BNP и NT-proBNP увеличивается при повышенной нагрузке на миокард. Не столь высокой является диагностическая ценность этих показателей в отделениях реанимации и интенсивной терапии, поскольку период полужизни BNP и NTproBNP довольно длительный и не может отображать резкие изменения состояния левого желудочка, которые происходят в результате интенсификации лечения. Не следует забывать и о состояниях, которые также могут влиять на концентрацию BNP и NT-proBNP - тахикардия, пожилой возраст, гипоксемия, гипертрофия левого желудочка, перегрузка правого желудочка, почечная дисфункция, цирроз печени, инфекционные заболевания, ишемия миокарда.

\section{ЛИТЕРАТУРА}

1. Kirsh B. Electronmicroscopy of the atrium of the Guinea pig heart. Exp. Med. Surg. 1956; 14: 99-112.

2. Marie J.P., Guillemont H., Hatt P.Y. Le degre de granulation des cardiocytes auriculaires. Etude planimetriques au cours de differents apports d'eau et de sodium chez le rat. Pathol. Biol. (Paris). 1976; 24: 549-554.

3. Henry J.P., Pearce J.W. The possible role of cardiac atrial stretch receptors in the induction of changes in urine flow. J. Physiol. 1956; 131: $572-585$.

4. De Bold A.J., Borenstein H.B., Veress A.T., Sonnenberg H. Rapid and important natriuretic response to intravenous injection of atrial myocardial extracts in rats. Life Sci. 1981; 28: 89-94.

5. Dahlen J.R. B-Type Natriuretic Peptide: Biochemistry and Measurement. In: Cardiac Markers. Ch. 23. A.Wu. Totowa (ed.). New Jersey. 2003. P. 369-377.

6. Levin E.R., Gardner D.G., Samson W.K. Natriuretic Peptides. N. Engl. J. Med. 1998; 339: 321-328.

7. Weber M., Hamm C. Role of B-type natriuretic peptide (BNP) and NT-proBNP in clinical routine. Heart. 2006; 92: 843-849.

8. Chauhan S.D., Nilsson H., Ahluwalia A., Hobbs A.J. Release of C-type natriuretic peptide accounts for the biological activity of

\section{Источник финансирования}

Статья подготовлена в рамках реализации проекта «Школа мастерства по терапии» Первого МГМУ им. И.М. Сеченова.

\section{Конфликт интересов}

Авторы данной статьи подтвердили отсутствие конфликта интересов, о котором необходимо сообщить. endothelium derived hyperpolarizing factor. Proc. Natl. Acad. Sci USA. 2003; 100 (3): 1426-1431.

9. Stingo A.J., Clavell A.L., Heublein D.M., Wei C.M., Pittelkow M.R., Burnett J.C. (Jr.). Presence of C-type natriuretic peptide in cultured human endothelial cells and plasma. Am. J. Physiol. 1992; 263 (4 Pt. 2): 1318-1321.

10. Chen H.H., Burnett J.C. (Jr.). C-type natriuretic peptide: the endothelial component of the natriuretic peptide system. J. Cardiovasc. Pharmacol. 1998; 32 (Suppl. 3): 22-28.

11. Kalra P.R., Anker S.D., Struthers A.D., Coats A.J. The role of C-type natriuretic peptide in cardiovascular medicine. Eur. Heart $J$. 2001; 22 (12): 997-1007

12. Wiley K.E., Davenport A.P. Physiological antagonism of endothelin-1 in human conductance and resistance coronary artery. Brit. J. Pharmacol. 2001; 133 (4): 568-774.

13. Drewett J.G., Fendly B.M., Garbers D.L., Lowe D.G. Natriuretic peptide receptor B (guanylyl cyclase B) mediates C-type natriuretic peptide relaxation of precontracted rat aorta. J. Biol. Chem. 1995; 270 (9): 4668-4674.

14. Clerico A., Recchia F.A., Passino C. Cardiac endocrine function is an essential component of the homeostatic regulation network: physiological and clinical implications. Am. J. Physiol. 2006; 290: 17-29. 
15. De Lemos J.A., McGuire D.K., Drazner M.H. B-type natriuretic peptide in cardiovascular disease. Lancet. 2003; 362(9380): 316-322.

16. Burnett J., Kao P., Hu D., Heser, D. W., Heublein, D., Granger, J.P. Atrial natriuretic peptide elevation in congestive heart failure in the human. Science. 1986; 231: 1145-1147.

17. Lerman A., Gibbons R., Rodeheffer R. Circulatory N terminal ANP as a marker for symptomless LV dysfunction. Lancet. 1993; 341: 1105-1109.

18. Motwani J., McAlpine H., Kennedy N., Struthers A. Plasma brain natriuretic peptide as an indicator for angiotensin converting enzyme inhibition after myocardial infarction. Lancet. 1993; 341: 1109-1113.

19. Hall C. The value of natriuretic peptides for the management of heart failure: current state of play. Eur. J. Heart Fail. 2001; 3: 395-397.

20. Галявич А.С., Мерясев С.Н., Галявич Р.А. Оценка тяжести и прогнозирование хронической сердечной недостаточности с помощью N-терминального промозгового натрийуретического пептида. Казанский медицинский журнал. 2009; 3: 319-323.

21. Осипова О.А. Оценка нейрогормональных систем у больных хронической сердечной недостаточностью, обусловленной постинфарктным кардиосклерозом. Человек и его здоровье. 2010; 1: 44-48.

22. Cowie M., Struthers A., Wood D., Coates A.J.S., Thompson S.G., Poole-Wilson P.A. Value of natriuretic peptides in assessment of patients with possible new heart failure in primary care. Lancet. 1997; 350: 1349-1353.

23. Tsutamoto T., Wada A., Maeda K., Fukai D. Attenuation of compensation of endogenous cardiac natriuretic peptide system in chronic heart failure. Circulation. 1997; 96: 509-516.

24. Clerico A., Emdin M. Diagnostic Accuracy and Prognostic Relevance of the Measurement of Cardiac Natriuretic Peptides: A Review. Clin. Chem. 2004; 50: 33-50.

25. Cheng V., Kazanegra R., Garcia A., Krishnaswamy P., Gardetto N., Clopton P., Maisel A. A rapid bedside test for B-type peptide predicts treatment outcomes in patients admitted for decompensated heart failure: a pilot study. JACC. 2001; 37: 386-391.

26. Dao Q., Krishnaswamy P., Kazanegra R., Harrison A., Amirnovin R., Lenert L., Clopton P., Alberto J., Hlavin P. Utility of B-type natriuretic peptide in the diagnosis of congestive heart failure in an urgent care setting. JACC. 2001; 37: 379-385.

27. Anand I., Fisher L., Chiang Y.T. , Latini R, Masson S., Maggioni A.P., Glazer R.D., Tognoni G., Cohn J.N. Changes in brain natriuretic peptide and norepinephrine over time and mortality and morbidity in the valsartan heart failure trial (Val-Heft). Circulation. 2003; 107: 1276-1281.

28. Galvani M., Ferrini D., Ottani F. Natriuretic peptides for risk stratification of patients with acute coronary syndromes. Eur. J. Heart Failure. 2004; 6: 327-334.
29. Murdoch D.R., McDonagh T.A., Byrne J., Blue L., Farmer R., Morton J.J., Dargie H.J. Titration of vasodilator therapy in chronic heart failure to plasma brain natriuretic peptide concentration: randomized comparison of the hemodynamic and neuroendocrine effects of tailored vs. empirical therapy. Am. Heart J. 1999; 138: 1126-1132.

30. Troughton R.W., Frampton C.M., Yandle T.G. et al.Treatment of heart failure guided by plasma aminoterminal brain natriuretic peptide (N-BNP) concentrations. Lancet 2000; 355 : 1126-1130.

31. Richards A.M., Doughty R., Nicholls M.G. , MacMahon S., Sharpe N., Murphy J., Espiner E.A., Frampton C., Yandle T.G. for the Australia - New Zealand Heart Failure Group. Plasma N terminal pro-brain natriuretic peptide and adrenomedullin: prognostic utility and prediction of benefit from carvedilol in chronic ischemic left ventricular dysfunction. J. Am. Coll. Cardiol. 2001; 37: 1781-1787.

32. Mills R.M., Le Jemtel T.H., Horton D.P., Liang C., Lang R, Silver M.A., Lui C., Chatterjee K. Sustained hemodynamic effects of an infusion of nesiritide (human $\beta$-type natriuretic peptide) in heart failure. J. Am. Coll. Cardiol. 1999; 34: 155162.

33. Colucci W.S., Elkayam U., Horton D.P., Elkayam U., Horton D.P., Abraham W.T., Bourge R.C., Johnson A.D., Wagoner L.E., Givertz M.M., Liang C.S., Neibaur M., Haught W.H., LeJemtel T.H. for the Nesiritide Study Group. Intravenous Nesiritide, a natriuretic peptide, in the treatment of decompensated congestive heart failure. N. Engl. J. Med. 2000; 343, 4: 246-253.

34. James B.Y. VMAC Committees. Intravenous Nesiritide vs Nitroglicerin for treatment of decompensated congestive heart failure. JAMA. 2002; 287: 1531-1540.

35. O'Connor C.M., Starling R.C., Hernandez A.F., Armstrong P.W., Dickstein K., Hasselblad V., Heizer G.M., Komajda M., Massie B.M. Effect of nesiritide in patients with acute decompensated heart failure. N. Engl. J. Med. 2011; 365: 32-43.

36. Chen H.H., Glockner J.F., Schirger J.A., Cataliotti A., Redfield M.M., Burnett J.C. (Jr.). Novel protein therapeutics for systolic heart failure: chronic subcutaneous B-type natriuretic peptide. $J$. Am. Coll. Cardiol. 2012; 60: 2305-2312.

37. McMurray J.J., Adamopoulos S., Anker S.D., Auricchio A., Böhm M., Dickstein K., Falk V., Filippatos G., Fonseca C., Gomez-Sanchez M.A., Jaarsma T., Køber L., Lip G.Y., Maggioni A.P., Parkhomenko A., Pieske B.M., Popescu B.A., Rønnevik P.K., Rutten F.H., Schwitter J., Seferovic P., Stepinska J., Trindade P.T., Voors A.A., Zannad F., Zeiher A. ESC guidelines for the diagnosis and treatment of acute and chronic heart failure 2012. The Task Force for the Diagnosis and Treatment of Acute and Chronic Heart Failure 2012 of the European Society of Cardiology. Developed in collaboration with the Heart Failure Association (HFA) of the ESC. Eur. J. Heart Fail. 2012; 14 (8): $803-869$.

\section{КОНТАКТНАЯ ИНФОРМАЦИЯ}

Напалков Дмитрий Александрович, доктор медицинских наук, профессор кафедры факультетской терапии № 1 лечебного факультета Первого МГМУ им. И.М. Сеченова Адрес: 119991, Москва, ул. Трубецкая, д. 8, с. 2, тел.: +7 (499) 248-53-30, e-mail: dminap@mail.ru

Бурнашева Гузаль Ахмедовна, студентка 6-го курса лечебного факультета Первого МГМУ им. И.М. Сеченова Адрес: 119991, Москва, ул. Трубецкая, д. 8, с. 2, тел.: +7 (499) 248-53-30, e-mail: Ledebouria@mail.ru 